\title{
From the Editor and Assistant Editor
}

\author{
DAVID F. GARCIA and STEPHEN STACKS
}

Even as our collective circumstances have fundamentally changed over these last four or so months, our work as editors of JSAM with authors and prospective authors has continued unabated as we shelter-in-place in Durham and Apex, North Carolina, respectively. It has been invigorating and reassuring to continue to receive your new submissions and to work through the editing and publication process with Mark Davidson and Jonathan Geffner. The excellent scholarship working its way through the various stages of this process has highlighted for us that even in these extraordinary times, our vital work together persists.

We want to take this opportunity to remind our readers that the Publishing Operations Director of Cambridge University Press has taken the unprecedented step of halting all journal issue printing from March 25, 2020 until further notice due to the impact of the coronavirus pandemic. Physical delivery of printed journals remains difficult, and this is causing problems with stock build-up and non-delivery which must be addressed. They do hope and expect to resume printing in the near future, as soon as the effects of this global disruption have subsided. Cambridge will still be publishing all JSAM issues online.

Stay safe and be well!

David Garcia, Editor

Stephen Stacks, Assistant Editor 